\title{
Impact of social support and self-efficacy on functioning in depressed older adults with chronic obstructive pulmonary disease
}

\author{
Patricia Marino \\ Jo Anne Sirey \\ Patrick J Raue \\ George S Alexopoulos \\ Department of Psychiatry, Weill \\ Medical College of Cornell University, \\ White Plains, NY, USA
}

\begin{abstract}
Objective: The objective of this study was to examine the association between social support, self-efficacy, and functioning among a sample of depressed older adults with chronic obstructive pulmonary disease (COPD).

Methods: Participants were recruited immediately following admission to an acute pulmonary rehabilitation unit of a rehabilitation hospital. One hundred and fifty-six subjects completed assessments of depression, functioning, social support, and self-efficacy at admission to the rehabilitation unit. Regression analyses were conducted to evaluate the impact of different aspects of social support and self-efficacy on overall functioning at admission.

Results: Controlling for depression, COPD severity, and age, subjective social support $(p=0.05)$ and self-efficacy $(\mathrm{p}<0.01)$ were associated with overall functioning.

Conclusion: The perception of social support as well as self-efficacy are important constructs related to overall functioning among depressed older adults with COPD. Attention to these psychosocial variables in health management interventions may help maintain or improve the overall functioning of depressed COPD patients.
\end{abstract}

Keywords: COPD, depression, social support, self-efficacy, functioning

\section{Introduction}

Chronic obstructive pulmonary disease (COPD), refers to a group of diseases that cause airflow limitation and respiration-related problems. It includes emphysema, chronic bronchitis, and in some cases asthma. COPD is a leading cause of death, illness, and disability in the United States. COPD afflicts approximately 17\% of men and $13 \%$ of women and is a major contributor to disability (ACCP/AACVPR 1997). In 2000, 119,000 deaths, 726,000 hospitalizations, and 1.5 million hospital emergency room visits were caused by COPD (CDCP 2007). COPD is a disabling illness with a deteriorating course that requires the implementation of a structured and demanding treatment regimen, and significant effort and tenacity on the part of patients. Treatment options usually include a combination of medication, oxygen therapy, and lifestyle changes including smoking cessation. There is no cure for COPD. Treatments are designed to slow decline, decrease disability, and maintain level of overall functioning.

Depression and its associated symptoms of anhedonia, helplessness, and hopelessness can further compromise an individual's participation in the treatment regimen required of COPD patients. Depression is the most common psychiatric disorder in adults with COPD. More than $25 \%$ of persons with COPD have depressive disorders (Borson et al 1998). In our own sample of adults with COPD who are admitted for pulmonary rehabilitation, $27 \%$ of those adults meet criteria for major depression (Alexopoulos and Latoussakis 2004). 
Depression worsens the outcomes of many medical disorders and increases the risk for falls (Sheeran et al 2004), suicide (Alexopoulos et al 2002; Blazer 2003), and nonsuicide mortality (Bruce and Leaf 1989; Bruce et al 1994; Gallo et al 2007). Comorbid depressive symptoms in patients with COPD have been found to be associated with poorer survival, longer hospitalization stay, increased symptom burden, and poorer physical and social functioning ( $\mathrm{Ng}$ et al 2007).

Among individuals with depression, a number of psychosocial factors can further affect adjustment to COPD and adherence to the complex medical regimens designed to slow decline, decrease disability, and maintain level of functioning. These factors include level of social support and self-efficacy, or one's perception in their ability to overcome specific challenges (Smith et al 2000; Airlie et al 2001).

There is a large body of evidence that documents the benefits of social support in patient recovery of both minor and major depression (Alexopoulos et al 1996; Hybel et al 2005; Nasser et al 2005; Lyness et al 2006) and improved health-promoting behaviors (Cohen 1988). Social support may contribute to a sense of acceptance that leads to an increase in self-esteem through the stability, predictability, and control that it provides (Cohen and Syme 1985; Rutter 1987). Self-efficacy has also been found to affect mental well-being and functioning through the individuals' belief in his or her ability to overcome specific challenges (Bandura 1997). There is evidence that self-efficacy plays an important role in improving exercise adherence in the COPD population (Davis et al 2006). Among various groups of chronically ill individuals, psychosocial factors including social support and self-efficacy have been found to affect overall functioning (Uchino et al 1996).

In this article, we investigate the impact of different dimensions of social support and self-efficacy on the overall functioning of depressed patients with COPD. We hypothesize that the benefits of both social support and self-efficacy will be evident regardless of age, depression severity, and physical health. In addition, we hypothesize that subjective social support will be a stronger predictor of overall functioning than other more objective dimensions of social support. We further examine whether the relationships of social support, self-efficacy, and overall functioning are moderated by age and severity of COPD.

\section{Methods}

Participants were consecutively admitted patients to the acute pulmonary rehabilitation unit of the Burke Rehabilitation Hospital, a university-affiliated hospital, and were recruited April 2002 to September 2007.
Participants who had the diagnosis of COPD, met Diagnostic and Statistical Manual of Mental Disorders (DSM-IV) criteria for unipolar major depressive disorder (MDD), and had a score of 17 or greater on the 24-item Hamilton Depression Rating Scale (HAM-D) were invited to take part in the study. The study received full review and approval from the Institutional Review Board of Weill Medical College of Cornell University and Burke Rehabilitation Hospital. All study participants provided signed informed consent.

\section{Assessments}

Depression symptoms, overall functioning, medical burden, pulmonary functioning, self-efficacy, and social support were assessed within 1-2 days of admission to the acute pulmonary rehabilitation unit of the Burke Rehabilitation Hospital. Assessments were administered by college graduates and masters-level research assistants who were trained and supervised by a study psychologist.

Depression symptoms were measured by the 24-item Hamilton Depression Rating Scale (HDRS) (Hamilton 1960). Based on joint independent ratings of 23 subjects the interrater reliability of assessors was 0.81 for the HDRS. Reliability was monitored regularly to prevent drift. The Duke Social Support Inventory (DSSI) was used to measure four dimensions of social support: network size, social interaction frequency, instrumental support, and subjective support (George et al 1989). Social network is defined as the number of individuals in the respondent's network. Social interaction is a measure of the frequency of the respondent's interaction with members of the support network. Instrumental support measures the tangible services that the respondent receives from network members. Subjective social support measures the respondent's perceptions of his/her inclusion as a valued and useful member of a social network; whether the network would provide help and support if needed; and general satisfaction with the quantity and quality of social support available. Self-efficacy was assessed using the Liverpoole Self-Efficacy Scale, an 11-item scale consisting of two domains: 1) control or sense of mastery; and 2) personal agency or ability to achieve desired outcomes (Airlie et al 2001).

Functioning was assessed with the 12-item World Health Organization Disability Assessment Schedule II (WHODAS II) (Epping-Jordan and Üstün 2000). The WHODAS II form is compatible with the international classification system of disability, is cross-culturally applicable, and treats all disorders at parity when determining level of 
overall functioning. The WHODAS II assess functioning in six domains: 1) understanding and communicating, 2) getting around, 3) self-care, 4) getting along with others, 5) household and work activities, and 6) participation in society in addition to overall functioning as defined by the total WHODAS II score. Medical burden was quantified with the Charlson Comborditity Index (CCI) (Charlson et al 1987). Functional status was assessed using the Pulmonary Functional Status and Dyspnea Questionnaire (PFSDQM), which measures dyspnea, fatigue, and changes in activities associated with key activities of interest in patients with pulmonary disease (Lareau et al 1998).

\section{Analysis}

The relationships between predictor variables (social support and self-efficacy) and the outcome of overall functioning variable (as defined by the WHODAS II total score) were first considered using linear regression analyses. Overall functioning is a continuous outcome variable ranging from 22 to 59 where lower scores indicate better overall functioning. A regression analysis was conducted for all independent variables that were significantly related to overall functioning. Age, severity of COPD as defined by pulmonary functioning, and depression severity were used as control variables in the final regression analysis. In supplementary analyses, we used a median split to dichotomize overall functioning to indicate better versus poorer overall functioning. This analysis was conducted to describe the clinical impact of the findings. Additional analyses were conducted to examine interaction effects of depression severity, age, and severity of COPD with significant predictor variables in order to test moderation effects.

\section{Results}

Two hundred twenty-four subjects met study criteria and were approached to take part in the study. One hundred and fifty-six subjects (69.6\%) completed data for baseline assessment. Of those who did not participate $44 \%$ refused participation, 25\% were too medically ill to participate, and $31 \%$ were excluded for either cognitive impairment or other psychiatric illnesses. The one hundred and fifty-six subjects who completed baseline ranged in age from 51-92 (mean $=71.3, \mathrm{SD}, 8.7)$, with $75 \%$ being $\geq 65$ years of age. The mean HDRS score at baseline was 24.7 (SD=3.8), indicating that many participants had moderate to severe depression. Sixty-seven percent were female. Their mean education was 13.2 years $(\mathrm{SD}=3.2) ; 87.9 \%$ were white; $3.9 \%$ were of Hispanic decent, and 37.8\% were married (Table 1).
Table I Demographic and clinical characteristics of the total sample

\begin{tabular}{llll}
\hline & M & SD & $\%$ \\
\hline Hamilton Depression Rating Scale & 24.7 & 3.8 & \\
Subjective social support & 18.4 & 2.5 & \\
Social network size & 4.7 & 4.2 & \\
Instrumental social support & 9.0 & 2.3 & \\
WHODAS total score & 37.4 & 6.5 & \\
Self-efficacy & 14.5 & 2.5 & \\
Dyspnea total & 156.4 & 54.9 & \\
Gender & & & \\
$\quad$ Male & & & 32.7 \\
$\quad$ Female & & & 67.3 \\
Current marital status & & & \\
$\quad$ Married & & & 37.8 \\
Widowed, separated, or divorced & & 51.9 \\
$\quad$ Single & & 10.3 \\
Race & & \\
$\quad$ Caucasian & & \\
$\quad$ Black/African American & & \\
Education & & \\
High school graduate or less & & \\
Some college & & \\
College graduate & & \\
\hline
\end{tabular}

\section{Relationship between predictor variables and overall functioning}

In preliminary regression models, social network size ( $\mathrm{p}<0.005)$, instrumental support $(\mathrm{p}<0.006)$, and subjective social support $(\mathrm{p}<0.001)$ predicted overall functioning as defined by the total WHODAS II score. Social interaction frequency was not significantly related to overall functioning. Higher scores on the control domain of self-efficacy ( $p<0.003$ ) predicted overall functioning. Depression as indicating by higher scores on the HDRS ( $p<0.001$ ) was also found to be related to overall functioning. Subsequent analysis adding self-efficacy and social support variables while controlling for age, COPD severity as indicated by pulmonary functioning, and depression severity found both subjective support and the control domain of self-efficacy to independently predict overall functioning (Table 2). In a supplementary analysis using a binary outcome of overall functioning, the results were replicated. Greater subjective social support $(\mathrm{OR}=0.93, \mathrm{p}=0.014)$ and greater self-efficacy $(\mathrm{OR}=0.79, \mathrm{p}=0.022)$ were independently associated with better overall functioning. 
Table 2 Cross-sectional model of psychosocial variables and overall functioning

\begin{tabular}{|c|c|c|c|c|}
\hline \multirow[t]{2}{*}{ Variables } & \multicolumn{2}{|c|}{$\begin{array}{l}\text { Unstandardized } \\
\text { coefficients }\end{array}$} & \multirow[t]{2}{*}{$\mathbf{t}$} & \multirow[t]{2}{*}{ Sig. } \\
\hline & B & $\begin{array}{l}\text { Std. } \\
\text { error }\end{array}$ & & \\
\hline Age & -0.051 & 0.053 & -0.948 & 0.346 \\
\hline $\begin{array}{l}\text { Pulmonary function } \\
\text { - Dyspnea }\end{array}$ & 0.009 & 0.009 & 0.985 & 0.327 \\
\hline $\begin{array}{l}\text { Depression severity } \\
\text { (HDRS score) }\end{array}$ & 0.509 & 0.122 & 4.175 & 0.000 \\
\hline Self-efficacy & -0.533 & 0.197 & -2.700 & 0.008 \\
\hline Social network size & -0.194 & 0.109 & -1.785 & 0.077 \\
\hline Subjective social support & -0.371 & 0.187 & -1.982 & 0.050 \\
\hline Instrumental social support & -0.046 & 0.216 & -0.212 & 0.833 \\
\hline
\end{tabular}

Note: Dependent variable: Overall functioning (WHODAS total).

To determine whether the predictive power of subjective support and self-efficacy to overall functioning varied according to severity of depression, severity of COPD, or age, we added interaction terms in separate models. No interactions were significant, indicating that both subjective social support and self-efficacy predicted overall functioning regardless of level of depression severity, severity of COPD, and age at initial assessment.

\section{Discussion}

The principal finding of this study is that subjective social support, self-efficacy, and depression were related to overall functioning in elderly depressed COPD patients. Both subjective social support and self-efficacy were independently related to overall functioning even in the context of severe medical illness and depression. While our current findings are consistent with research indicating that social support predicts objective health outcomes and disability, even after controlling for demographic variables and COPD (House et al 1988; Kiecolt-Glaser et al 1991), few studies have investigated these relationships in the context COPD and depression. It is striking that among this patient population with severe medical illnesses and comorbid depression, the psychosocial factors of social support and self-efficacy remain related to overall functioning.

A possible explanation for the benefits of subjective social support is that the belief concerning the quality of one's relationships (Lakey and Cassidy 1990), rather than the size of the social network or the amount of information provided by the social network affects outcome. Social support may be related to well-being by providing a sense of predictability and stability in one's life situation (Cohen and Wills 1985).
Additionally, subjective social support may play a role in improving adherence to the often grueling medical regimen faced by COPD patients.

Self-efficacy theory maintains that an individual's sense of personal control and mastery plays an important role in improving overall functioning as well as other aspects of illness management (McCathie et al 2002). This theory is supported by our current findings that indicate the significant role of self-efficacy in overall functioning in a COPD population after controlling for age, illness severity, and depression. Kohler and colleagues (2002) also indicated that in their sample of COPD patients, individuals with low perceived self-efficacy were more limited in functioning than those with equally severe disease but who had higher perceived self-efficacy for carrying out activities.

It is well supported in the literature that the course of disability parallels the course of depression (Von Korff et al 1992; Ormel et al 1993), such that depression and disability interact with each other in a variety of ways creating a spiraling relationship (Bruce 2002). Effective treatment of depression has been found to significantly improve physical functioning in a sample of older adults with major depressive disorder (Callahan et al 2005). Additionally, among an inpatient COPD population the interaction of baseline disability and severity of depression was significantly associated with change in disability at discharge (Alexopoulos et al 2006).

Attention to subjective social support and self-efficacy in health management interventions may help improve or maintain the overall functioning of depressed COPD patients. The relationship between social support and selfefficacy in health management is further supported by the stress-buffering model of social support which, in which the beneficial mechanisms of social support include (a) increasing feelings of self-esteem; (b) increasing control over one's environment; (b) providing information; (c) exerting social norms that encourage adaptive behaviors; and (d) providing tangible aid and resources (Wills 1985; Dinges and Joos 1988). Enhancing social support and self-efficacy has been shown to correlate with improved health-related adherence and quality of life among individuals with chronic medical illnesses (Aalto et al 1997; Simoni et al 2006). Additionally, those with low sense of control and limited social support have been found to be less likely to engage in healthy behaviors (Cardarelli et al 2007).

Our results must be considered in the context of the study limitations. This is a cross sectional study; therefore we are unable to examine predictive qualities of the psychosocial factors and depression on overall functioning. The study 
also did not include a comparison group, which would allow us to determine the impact of psychosocial factors among nondepressed individuals or individuals not admitted to pulmonary rehabilitation hospital.

Additionally, the study does not provide a causal pathway between the key predictors of social support, self-efficacy, and depression with functioning. Thus, we are not clear on how these factors affect outcome. Finally, the study also suffered from the limitations of all self-report studies in that the participants' responses may have been influenced by social desirability.

\section{Conclusion}

In summary, the current findings indicate that subjective social support, self-efficacy, and depression affect overall functioning among an older adult COPD population. The results also highlight the importance of subjective social support and self-efficacy in the context of improving health management and adherence to the demanding treatment regimen endured by COPD patients in order to maintain or improve overall functioning.

From both the research and clinical perspective, these findings provide strong evidence that interventions targeted at social support, fostering self-efficacy and reducing depression may improve and maintain overall functioning among this chronically ill population. Further research may examine the predictive nature of social support and self-efficacy on the improvement and maintenance of overall functioning, and the causal pathway between these variables.

\section{Acknowledgment}

The National Institute of Mental Health (P30 MH68638, R01 MH075897, R01 HL071992) and the Sanchez Foundation supported this research. The authors report no conflicts of interest in this work.

\section{References}

Aalto AM, Utela A, Aro AR. 1997. Health related quality of life among insulin-dependent diabetics: disease-related and psychosocial correlates. Patient Educ Counsel, 30:215-25.

[ACCP/AACVPR] American College of Chest Physicians, American Association of Cardiovascular and Pulmonary Rehabilitation; Pulmonary Rehabilitation Guidelines Panel. 1997. Pulmonary rehabilitation: Joint ACCP/AACVPR evidence-based guidelines. J Cardiopulm Rehabil, 17:371-405.

Airlie J, Baker GA, Smith SJ, et al. 2001. Measuring the impact of multiple sclerosis on psychosocial functioning: the development of a new selfefficacy scale. Clin Rehabil, 15:259-65.

Alexopoulos GS, Meyers BS, Young RC, et al. 1996. Recovery in geriatric depression. Arch Gen Psychiatry, 53:305-12.
Alexopoulos GS, Kiossis D, Klimstra S, et al. 2002. Clinical presentation of the "depression-executive dysfunction syndrome" of late life. Am J Geriatr Psychiatry, 10:98-106.

Alexopoulos GS, Latoussakis V. 2004. Depression comorbidity with COPD. Psych Ann, 34:289-96.

Alexopoulos GS, Sirey JA, Raue Patrick J, et al. 2006. Outcomes of depressed patients undergoing inpatient pulmonary rehabilitation. Am J Geriatr Psychiatry, 14:466-75.

Bandura A. 1997. Self-efficacy: The exercise of control. New York: WH Feeman and Co.

Blazer DG. 2003. Depression in late life: Review and commentary. $J$ Gerontol Med Sci, 56A:249-65.

Borson S, Claypoole K, McDonald GJ. 1998. Depression and chronic obstructive pulmonary disease: Treatment trials. Semin Clin Neuropsychiatry, 3:115-30.

Bruce ML, Hoff RA. 1994. Social and physical health risk factors for firstonset major depressive disorder in a community sample. Soc Psychiatry Psychiatr Epidemiol, 29:165-71.

Bruce ML, McAvay GJ, Raue PJ, et al. 2002. Major depression in elderly home health care patients. Am J Psychiatry, 159:1367-74.

Bruce ML, Leaf PJ. 1989. Psychiatric disorders and 15 month mortality in a community sample of older adults. Am J Public Health, 79:727-30.

Callahan CM, Kroenke K, Counsell SR, et al; IMPACT investigators. 2005. Treatment of depression improves physical functioning in older adults. J Am Geriatr Soc, 53:543-4.

Cardarelli KM, Vernon SW, Baumler ER, et al. 2007. Sense of control and diabetes mellitus among US adults: A cross-sectional analysis. Biopsychosoc Med, 1:1-19.

[CDCP] Centers for Disease Control and Prevention. 2007. Environmental hazards and health effects: Chronic obstructive pulmonary disease [online]. Accessed December 17, 2007. URL: http://www.cdc.gov/nceh/ airpollution/copd/\#gen.

Charlson ME, Pompei P, Ales KL, et al. 1987. A new method of classifying prognosis comorbidity in lognitudinal studies: development and validation. J Chron Dis, 40:373-83.

Cohen J. 1988. Statistical power analysis for the behavioral sciences. Hillsdale, New Jersey: Lawrence Erlbaum.

Cohen S, Syme SL. 1985. Social support and health. Orlando, FL: Academic Press.

Cohen S, Wills TA. 1985. Stress, social support, and the buffering hypothesis. Psychol Bull, 98:310-57.

Davis AHT, Carrieri-Kohlman V, Janson SL, et al. 2006. Effects of treatment on two types of self-efficacy in people with chronic obstructive pulmonary disease. J Pain Sympt Manage, 32:60-70.

Dinges NG, Joos SK. 1988. Stress, coping, and health: Models of interactions for Indian and Native populations. Am Indian Alsk Native Ment Health Res Monogr Ser, 1:8-64.

Epping-Jordan JA, Üstün TB. 2000. The WHODAS-II: leveling the playing field for all disorders. Bull WHO, 6:5-6.

Gallo JJ, Bogner HR, Morales KH, et al. 2007. Depression, cardiovascular disease, diabetes, and 2-year mortality among older primary care patients. Am J Geritr Psychiatry, 146:689-98.

George LK, Blazer DG, Hughes DC, et al. 1989. Social support and the outcome of major depression. Br J Psychiatry, 154:478-85.

Hamilton M. 1960. A rating scale for depression. J Neurol Neurosurg Psychiatry, 23:56-62.

Hybels CF, Blazer DG, Steffens DC. 2005. Predictors of partial remission in older patients treated for major depression: The role of comorbid dysthymia. Am J Geriatr Psychiatry, 13:713-21.

House JS, Landis KR, Umberson D. 1988. Social relationships and health. Science, 241:540-5.

Kiecolt-Glaser JK, Dura JR, Speicher CE, et al. 1991. Spousal caregivers of dementia victims: Longitudinal changes in immunity and health. Psychosom Med, 53:345-62.

Kohler CL, Fish L, Greene PG. 2002. The relationship of perceived selfefficacy to quality of life in chronic obstructive pulmonary disease Health Psychol, 21:610-14. 
Lakey B, Cassady PB. 1990. Cognitive processes in perceived social support. J Personal Soc Psychol, 59:337-43.

Lareau SC, Meek Paula M, Roos Philip J. 1998. Development and testing of the modified version of the Pulmonary Functional Status and Dyspnea Questionnaire (PFSDQ-M). Heart Lung, 27:159-68.

Lyness JM, Heo M, Datto CJ, et al. 2006. Outcomes of minor and subsyndromal depression among elderly patient in primary care settings. Ann Intern Med, 144:496-505.

McCathie HCF, Spence S, Tate RL. 2002. Adjustment to chronic obstructive pulmonary disease: the importance of psychological factors. Eur Respir J, 19:47-53.

Nasser EH, Overholser JC. 2005. Recovery from major depression: The role of support from family, friends, and spiritual beliefs. Acta Psychiatry Scanda, 111:125-32.

Ng TP, Niti M, Tan WC, et al. 2007. Depressive symptoms and chronic obstructive pulmonary disease: effect on mortality, hospital readmission, symptom burden, functional status, and quality of life. Arch Intern Med, 167:60-7.

Ormel J, Von Korff M, Van den Brink W, et al. 1993. Depression, anxiety, and social disability show synchrony of change in primary care patients. Am J Public Health, 83:385-90.
Rutter M. 1987. Psychosocial resilience and protect mechanisms. Am J Orthopsychiatry, 57:316-31.

Sheeran T, Brown EL, Nassisi P, et al. 2004. Does depression predict falls among home health patients? Using a clinical-research partnership to improve the quality of geriatric care. Home Healthc Nurse, 22:384-9.

Simoni JM, Frick PA, Huang B. 2006. A longitudinal evaluation of a social support model of medication adherence among HIV-positive men and women on antiretroviral therapy. Health Psychology, 25:74-81.

Smith GC, Kohn SJ, Savage-Stevens SE, et al. 2000. The effects of interpersonal and personal agency on perceived control and psychological well-being in adulthood. Gerontologist, 40:458-68.

Uchino B, Cacioppo JT, Kiecolt-Glaser JK. 1996. The relationship between social support and phsyiological process: a review with emphasis on underlying mechanisms and implications for health. Psychol Bull, 119:488-531.

Von Korff M, Ormel J, Katon W, et al. 1992. Disability and depression among high utilizers of health care. A longitudinal analysis. Arch Gen Psychiatry, 49:91-100.

Wills TA. 1985. Supportive functions of interpersonal relationships. In: Cohen S, Syme SL (eds.). Social support and health. Orlando, FL: Academic Press, pp. 61-82. 